23

\title{
Изучение корреляций содержания клинически важных жирных кислот в пище и крови со спектрами поглощения ближнего инфракрасного диапазона
}

\author{
(C) А.В. Калинин ${ }^{1}$, В.Н. Крашенинников ${ }^{1}$, В.Н. Титов ${ }^{2}$ \\ ${ }^{1}$ Институт спектроскопии РАН, \\ 142190 Троицк, Москва, Россия \\ 2 „Национальный медицинский исследовательский центр кардиологии“ Минздрава РФ, \\ 121552 Москва, Россия \\ e-mail: kalinin@isan.troitsk.ru
}

Поступила в редакцию 25.02.2019 г.

В окончательной редакции 25.02.2019 г.

Принята к публикации 15.03.2019 г.

\begin{abstract}
Триглицериды жирных кислот являются существенными компонентами диеты человека, обладая при этом уникальной биологической активностью. Их содержание в биологических средах традиционно определяется способами газовой и жидкостной хроматографии. Из-за сложности этих методов они малодоступны для массового анализа пищевых продуктов и сыворотки крови. Цель нашей работы - изучить корреляции спектров поглощения ближнего инфракрасного излучения с характерными колебаниями функциональных групп клинически важных жирных кислот, таких как пальмитиновая насыщенная, олеиновая и линолевая ненасышенные, их транс-изомеры и другие, а также разработать приемы и испытать аппаратуру для оперативной оценки их содержания в жировых продуктах и сыворотке крови. В результате получены доказательства применимости фурье-спектрометра в диапазоне длин волн 1.0-2.4 $\mu \mathrm{m}$ для оперативного анализа клинически важных жирных кислот в сливочном масле, спредах и в сыворотке крови, а также установлена корреляция спектров поглощения сыворотки с содержанием в ней общих триглицеридов и холестерина. Кроме того, с помощью портативного спектрометра в диапазоне длин волн 1.0-1.65 $\mu \mathrm{m}$, пригодного для массового анализа качества масложировых продуктов, определены содержание названных жирных кислот и изучена селективность их определения.
\end{abstract}

Ключевые слова: триглицериды жирных кислот, транс-изомеры, ближняя инфракрасная спектрометрия, сливочное масло, пальмовое масло, сыворотка крови.

DOI: $10.21883 /$ OS.2019.07.47940.103-19

\section{Введение}

Общеизвестно [1-3], что сердечно-сосудистые и раковые заболевания (главные причины смерти людей) статистически связаны с избыточным содержанием в пище и в крови триглицеридов насыщенных жирных кислот (ЖК) по отношению к ненасыщенным ЖК. К наиболее значимым следует отнести насыщенную пальмитиновую (C16:0) и ненасыщенные (ННЖК) олеиновую (C18:1) и линолевую $(\mathrm{C} 18: 2)$ ЖК. Известны также результаты прослеживания связи состояния перегрузки организма спортсменов с изменением ЖК-профиля плазмы крови, причем, насколько нам известно, впервые в этом исследовании была применена ИК спектрометрия [4]. Следует также учитывать, что двойная связь (ДС) в цепи атомов углерода ненасыщенных ЖК реализуется в различных пространственных формах: транс- и цис-конфигурациях. Если фрагменты единой цепи мононенасыщенных ЖК (МЖК) и ННЖК расположены по одну сторону от ДС, образуется физиологичная иис-изомерная форма; если же фрагменты ЖК расположены по разные стороны относительно ДС, формируется афизиологичная транс-изомерная форма. Физико-химические параметры
МЖК в форме цис- и транс-изомеров существенно отличаются [5]. Для других ННЖК, как и для МЖК, транс-изомерия обусловлена отличной от цис-изомерии ориентацией участков цепи атомов углерода относительно ДС.

Афизиологичные транс-МЖК присутствуют в триглицеридах во многих продуктах. Чаще всего трансформой олеиновой $\omega-9$ С $18: 1$ ицс-ЖК является $\omega$-9 C18:1 транс-элаидиновая МЖК. Изомером олеиновой ЖК является также и $\omega$-7 С18:1 транс-вакценовая МЖК. Это один из немногих транс-изомеров, которые присутствуют в составе многих натуральных жиров и в мясе. Химически оптимальное количество элаидиновой транс-ЖК присутствует в растительных маслах. В отличие от искусственных транс-ЖК, содержание которых прежде составляло в маргаринах внушительные количества (до $40 \%$ всех ЖК), натуральные трансМЖК и транс-ННЖК содержатся в пище постоянно в количестве до 6-8\% от всех ЖК [6].

Традиционные методы определения содержания ЖК газовая и жидкостная хроматография - малопригодны для массовых применений в лабораториях пищевой и 
клинической биохимии вследствие неоперативности, сложности пробоподготовки и дороговизны анализа.

Более оперативным методом анализа ЖК даже при необходимости их экстрагирования из масложировых продуктов является спектрометрия фундаментального поглощения молекулами ЖК излучения среднего ИК диапазона. Для исключения необходимости экстракции жировой фазы из продуктов Американским обществом химиков в качестве стандартного метода контроля качества жиров и масел в начале века был принят метод нарушенного внутреннего отражения (НПВО) в среднем ИК диапазоне. Однако он даёт только количественную оценку функциональных групп, таких как насыщенные ЖК, транс-ЖК и другие. С другой стороны, анализ поглощения обертонами и комбинациями основных колебаний связей функциональных групп молекул ЖК в ближнем инфракрасном (БИК) диапазоне позволяет избежать необходимости извлечения жировой фазы из образца и существенно упростить измерения. Поэтому в период с 2004 по 2014 годы был выполнен цикл работ, представленных в [7,8], по разработке метода классификации и количественной оценки ЖК пищевых масел и жиров с использованием фурье-спектрометров БИК диапазона и данных газовой хроматографии на основе хемометрического подхода (ПЛС-регрессии). Было установлено, что метод БИК-поглощения в комбинации с ПЛС-регрессией может быть использован для быстрого мониторинга качества жировых продуктов, в том числе для целей маркировки и обнаружения фальсификаций.

Для удовлетворения потребностей пищевой, фармацевтической промышленности и клинической практики в массовых анализах названных ЖК востребован оперативный и, в ряде применений, портативный спектрометранализатор. Поэтому наша цель - изучить параметры корреляций и разработать метод оперативного определения содержания клинически важных ЖК, включая транс-изомеры, в продуктах питания и в сыворотке крови пациентов с помощью БИК-спектрофотометров, в том числе портативных.

Следует отметить, что для массовой проверки жировых продуктов на соответствие уровня суммы трансЖК действующему в РФ ограничению в $2 \%$ жировой фазы целесообразно применить менее дорогой и сложный, чем фурье-спектрометр, спектральный прибор дифракционный спектрометр с многоэлементным приемником, имеющий к тому же известные преимущества для количественного анализа фотометрических параметров [9]. Поэтому второй целью настоящей работы было повышение эффективности определения клинически значимых триглицеридов ЖК в масложировых продуктах и сыворотке крови пациентов с помощью созданного ранее портативного БИК-спектрометра с многоэлементным фотоприемником - линейкой InGaAs-фотодиодов [10].

Поскольку задача определения содержания компонент смеси по спектрам поглощения является некорректной (допускающей неоднозначные решения), актуальным является изучение селективности (специфичности) опре- деления с применением ПЛС-регрессии, в том числе с учетом имеющихся к настоящему времени сведений об отнесении характерных для определяемых молекул колебаний к характеристикам наблюдаемого спектра поглощения масложировой смеси [11]. С другой стороны, возможен экспериментальный подход изучения повторяемости показания о содержании компонента аналита - при вариации предполагаемого .мешающего. компонента в партии образцов. Результаты применения этих подходов для оценки селективности определения ряда клинически значимых ЖК изложены в настоящей работе.

\section{Материалы и методы}

\section{Приготовление партий стандартных калибровочных и тестовых образцов и исследуемых продуктов}

Многокомпонентная калибровка спектрометров для анализа смесей триглицеридов ЖК включает трудоемкую процедуру измерения спектров большого числа стандартных образцов с вариацией концентраций нескольких (не только определяемых, но и интерферирующих, „мешающих“) компонент. Для калибровки по одному компоненту требуется около 10 стандартных образцов с вариацией концентрации, для калибровки по 2-м компонентам количество образцов увеличивается до 100 шт., для 3-х компонентов - до 1000 шт. и так далее [12], что создает значительные трудности в многокомпонентной калибровке.

Для преодоления последнего затруднения нами ранее [13] развит и испытан метод „экономного“ конструирования калибровочной партии образцов. Традиционно изыскиваются партии с хаотическими распределениями концентраций. Мы проверили „экономный“ способ ПЛС-калибровки спектрометра с линейным InGaAsфотоприемником, который был эффективен для определения содержания 3-х компонент при специальном выборе распределений концентраций компонент в партии из всего лишь 35 стандартных калибровочных образцов. Он основан на включении в калибровку лишь пограничных, приосевых и центральных образцов (по концентрациям компонент) и исключении из неё образцов с промежуточными концентрациями (и использовании их для тестирования). Количество из 35 калибровочных и 15-18 тестовых образцов, по нашему мнению, приемлемо по трудоемкости их изготовления и качеству получаемых моделей.

Аналогичный подход осуществлен в настоящей работе при построении ПЛС-моделей по образцам партии № 1 (табл. 1) для определения доли молочного жира по содержанию в них C4:0, C14:0 и C16:0 НЖК, а также по образцам партий № 2 и № 3 для определения содержания ЖК С16:0, С18:1uис и С18:1транс + C18:2транс в смесях молочного и говяжьего жиров, пальмового и подсолнечного масел. Для создания заданных вариаций 
Таблица 1. Диапазоны долей индивидуальных ЖК в mass \% в партиях калибровочных и тестовых образцов масложировых смесей: $T T$ - сумма транс-ЖК $\mathrm{C} 18: 1 \mathrm{t}+18: 2 \mathrm{t}, M F$ - доля молочного жира

\begin{tabular}{c|c|c|c|c|c|c|c|c}
\hline Set №(number of sp.) & C4:0 & C14:0 & C16:0 & C18:0 & C18:1 & C18:2 & $T T$ & $M F$ \\
\hline $1(50)$ & $0.5-4.2$ & $6.0-14.0$ & $14.0-3.0$ & $2.5-8.5$ & $21.0-42.0$ & $2.5-8.5$ & $1.1-3.9$ & $20-80$ \\
$2(51)$ & $0.5-3.0$ & $5.0-11.0$ & $14.0-5.0$ & $2.3-3.8$ & $24.0-48.0$ & $2.3-3.8$ & $1.2-3.1$ & $20-70$ \\
$3(35)$ & $0-3.4$ & $1.0-0.3$ & $21.1-2.3$ & $3.8-1.3$ & $18.1-42.1$ & $3.8-11.3$ & $0.3-3.3$ & $10-99$
\end{tabular}

долей трех ЖК в партиях образцов был использован, кроме исходных материалов, также разбавитель - октан, Fluka Analytical. Извлечение жиров и масел из исследуемых пищевых продуктов выполнено без применения растворителей в соответствии с приемами, которые описаны ранее $[14,15]$ :

a) продукт нагревали до $60^{\circ} \mathrm{C}$ и центрифугировали при $4000 \mathrm{rot} / \mathrm{s}$ в течение $6-18 \mathrm{~min}$;

б) нижнюю водную фракцию сливали через отверстие в пробирке;

в) верхнюю часть (иногда с протеин-содержащей пеной) отфильтровывали в термостате при $60^{\circ} \mathrm{C}$.

Партии стандартных образцов масложировых смесей получали смешиванием рассчитанных по „экономному“ способу навесок исходных материалов: спредов, маргаринов, сливочного, пальмового, подсолнечного, пальмоядрового, кокосового масел, предварительно измеренных по содержанию ЖК с помощью газового хроматографа Кристаллюкс 4000М (производитель ООО Интехром, РФ) в соответствии с ГОСТ Р 51483-99 „Масла растительные и жиры животные. Определение методом газовой хроматографии массовой доли метиловых эфиров индивидуальных ЖК к их сумме“, с предварительной калибровкой хроматографа по смеси стандартов метиловых эфиров ЖК (F.A.M.E., Mix C4-C24, Supelco, кат. № 18919). Затем содержание семи ЖК, названных в табл. 1, в трех партиях калибровочных и тестовых образцов проверяли измерением на том же хроматографе. Хранили образцы при комнатной температуре в „мягких“ условиях (во избежание переэтерификации) в соответствии с [15] и использовали для спектрометрии в течение двух недель. Перед измерением в БИКспектрометрах образцы нагревали до $60^{\circ} \mathrm{C}$ в термостате. Температура образца $59 \pm 1{ }^{\circ} \mathrm{C}$ выбрана, с одной стороны, для полного расплавления ЖК, а с другой - для исключения их переэтерификации.

Кроме того, для настоящей работы были получены четыре партии сыворотки крови $(27,30,42$ и 28 образцов), подвергнутых стандартному клиническому анализу в процессе терапии у различных пациентов клинического отделения НИИ кардиологии Российского кардиологического научно-производственного комплекса МЗ РФ (табл. 2).

Содержание в них общих триглицеридов (TG) и общего холестерина $(\mathrm{Ch})$ было измерено стандартными ферментативными методами (GPO-PAP)7743-Триглицериды-Ново, с жидкой формой Миура, 250 и (CHOD-
РАР)7751-Холестерин-Ново, с Миура, 250 соответственно, а индивидуальных триглицеридов ЖК - традиционной экстракцией, метилированием и разделением индивидуальных ЖК с помощью высокоэффективного жидкостного хроматографа DIONEX Ultimate 3000 с использованием колонки Reprosil-Pur с наполнителем C18-AQ $3 \mu \mathrm{m}, 150 \times 4.6 \mathrm{~mm}$. В качестве детектора использовали масс-спектрометр модели ABSCIEX QTRAP 5500 при работе в режиме регистрации положительно заряженных ионов. После измерения вышеназванными стандартными методами образцы сыворотки замораживались до $-8^{\circ} \mathrm{C}$, хранились не более трех недель и затем размораживались для регистрации их спектров поглощения.

\section{Регистрация спектров}

Спектры поглощения партий № 1-№ 3 стандартных образцов смесей, отличающиеся значительной вариацией концентраций ННЖК и содержащих молочный жир, были измерены в 10-миллиметровой кювете с помощью созданного в Институте спектроскопии РАН дифракционного спектрометра с линейкой InGaAs-диодов [16] (далее IGA-спектрометр) в диапазоне длин волн $1100-1650 \mathrm{~nm}$ со спектральным разрешением $10 \mathrm{~nm}$ при времени накопления $40 \mathrm{~s}$. Последнюю модификацию прибора отличает термостатирование кюветного отделения (рис. 1), что позволило регистрировать спектры при установившейся температуре образца $59 \pm 1^{\circ} \mathrm{C}$. Время измерения одного образца не превышало $2.5-3 \mathrm{~min}$.

Спектры поглощения образцов тех же трех партий масложировых смесей были измерены с помощью фурье-спектрометра MPA (Bruker AG, Германия) в диапазоне длин волн $800-2400 \mathrm{~nm}$ с разрешением $2 \mathrm{~nm}$ в круглой кварцевой пробирке внутренним диаметром $6.0 \mathrm{~mm}$ при времени накопления $4 \mathrm{~min}$ (64 скана) и температуре образца $59 \pm 1^{\circ} \mathrm{C}$.

Спектры поглощения спредов, сливочного масла, заменителя молочного жира (после извлечения из них масложировой фракции) были измерены с помощью IGA-спектрометра при тех же, что и стандартные образцы, условиях и использованы для оценки показателей их качества.

Спектрометрия четырех партий сыворотки крови была выполнена как с помощью фурье-спектрометра МРА 
Таблица 2. Диапазоны вариаций долей индивидуальных ЖК в mass \% и концентраций холестерина Сh и триглицеридов TG в $\mathrm{mmol} / \mathrm{l}$ в партиях калибровочных и тестовых образцов сыворотки кардио-пациентов

\begin{tabular}{c|c|c|c|c|c|c|c|c}
\hline Set №(number of sp.) & C14:0, \% & C16:0, \% & C18:0, \% & C18:1, \% & C18:2, \% & C20:4, \% & $C h, \mathrm{mmol} / 1$ & $T G, \mathrm{mmol} / 1$ \\
\hline $1(27)$ & $6.0-14.0$ & $18.0-35.3$ & $2.5-8.5$ & $21.0-32.0$ & $22.5-38.5$ & - & $0.1-7.1$ & $0.3-8.8$ \\
$2(35)$ & $5.0-11.0$ & $22.4-50.1$ & $2.3-3.8$ & $24.0-38.0$ & $23.7-39.8$ & $1.8-5.4$ & $3.0-4.5$ & $0.4-5.9$ \\
$3(42)$ & $2.0-18.3$ & $21.1-36.6$ & $3.8-13.1$ & $18.1-32.1$ & $28.5-41.3$ & $2.1-4.5$ & - & - \\
$4(28)$ & $3.1-21.4$ & $22.3-34.1$ & $5.1-7.8$ & $16.3-31.3$ & $27.6-39.5$ & $3.7-6.5$ & $2.4-7.8$ & $0.5-7.6$
\end{tabular}

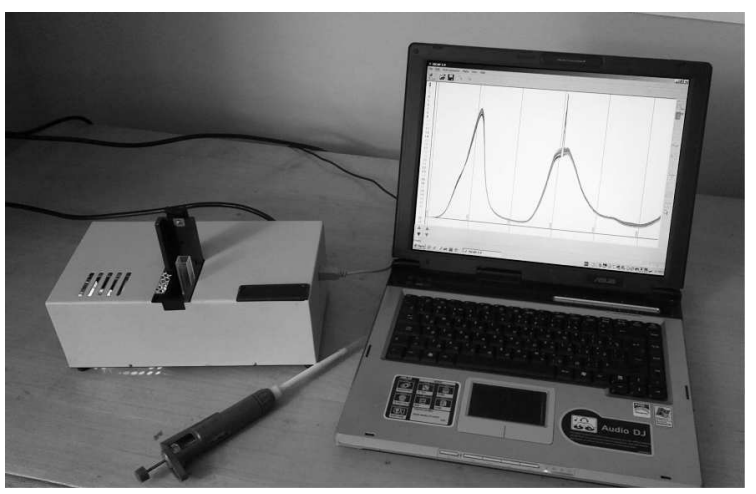

Рис. 1. Фото портативного спектрофотометра на линейке InGaAs-диодов для диапазона длин волн $1100-1650 \mathrm{~nm}$.

(Bruker AG), так и посредством IGA-спектрометра. Даже при максимальном содержании триглицеридов ЖКспектрометрия в БИК-диапазоне затруднена доминирующим поглощением воды. Поэтому в обоих случаях референтом служила кювета с дистиллированной водой для исключения её влияния на спектры. Ранее мы установили возможность определять индивидуальные ЖК в масложировых смесях с небольшим (до 6\%) уровнем воды по обертонам и комбинациям полос фундаментального поглощения вблизи $1150,1400,1700 \mathrm{~nm}$, причем оптическая плотность последней полосы была примерно в 4 раза выше первой [12]. Для выделения поглощения ЖХ на фоне поглощения воды мы воспользовались совпадением положений в спектрах пика поглощения жиров вблизи $1700 \mathrm{~nm}$ и относительного провала поглощения воды, показанного на рис. 2, $a$. В диапазоне длин волн 1350-1660 nm сигнал имеет уровни вне предела фотометрической шкалы прибора, поэтому спектры на этом участке спрямлены (рис. $3, b, c)$.

\section{Построение и тестирование калибровочных моделей}

По спектрам и значениям массовых долей семи вышеназванным ЖК и доле молочного жира в калибровочных масложировых образцах и образцах сыворотки крови с помощью программы ПЛС-регрессии ISCAP, которая описана ранее [10], было построено множество калибровочных моделей, которые отличались диапазонами спектров, способами предобработки спектров, составом

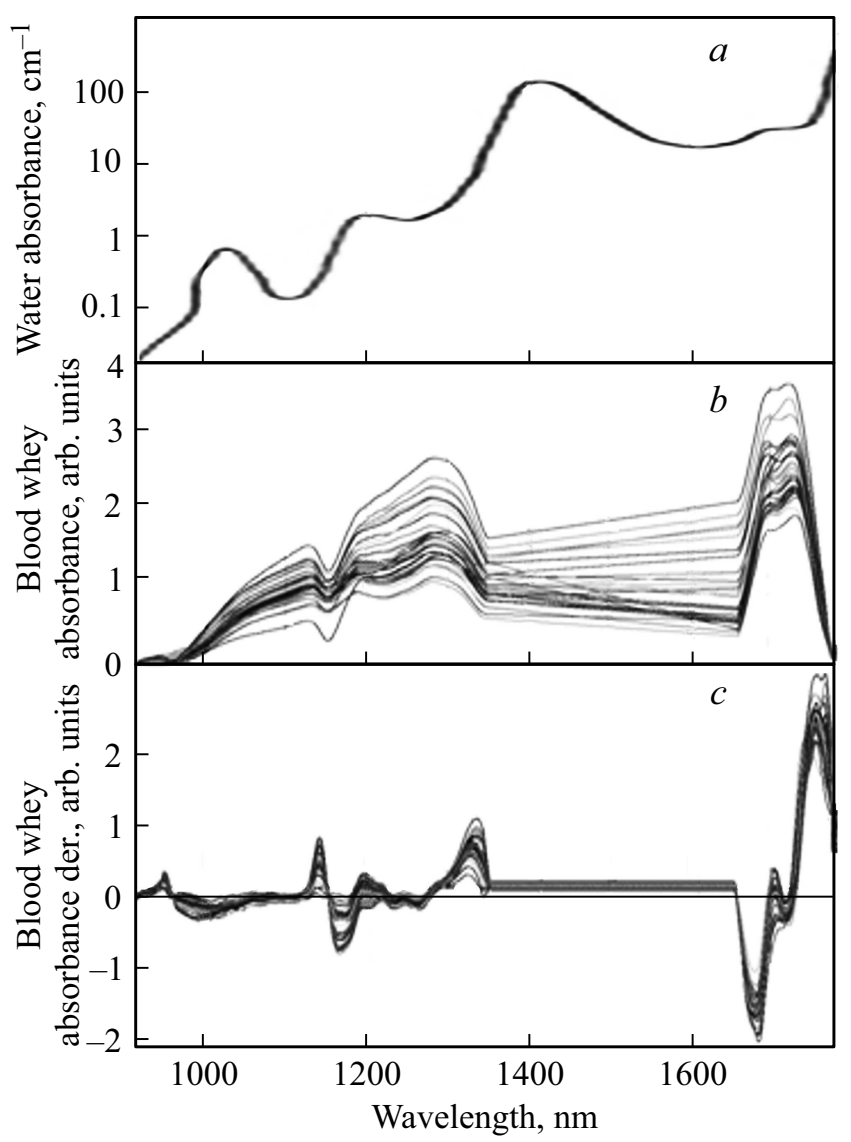

Рис. 2. Спектральные значения: (a) коэффициента поглощения воды (в логарифмической шкале), $(b)$ оптической плотности 27 калибровочных образцов сыворотки (в диапазоне длин волн 1350-1660 nm уровни спектров находятся вне предела фотометрической шкалы прибора), (c) продифференцированной оптической плотности тех же образцов.

образцов в калибровочной партии. В моделях по спектрам фурье-спектрометров использовали полный спектральный диапазон $(1100-2400 \mathrm{~nm})$ и три поддиапазона: $1100-1650,1100-1880$ и 1500-2400 nm (для которых компанией Hamamatsu, Япония, производятся линейки InGaAs-фотодиодов). Все ПЛС-модели были протестированы по партиям стандартных образцов, которые не использовались для калибровки. Эффективность ПЛСмоделей в соответствии с [17] была оценена значениями: сложности $n$, коэффициента множественной кор- 


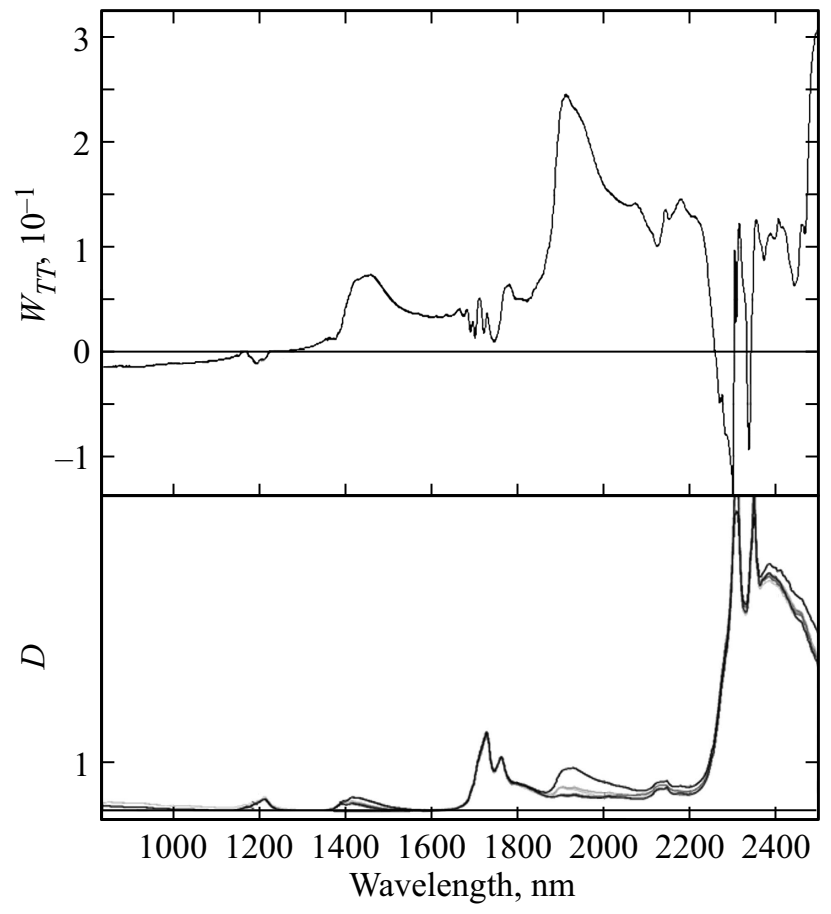

Pис. 3. Вверху: вектор регрессионных коэффициентов WTT модели MPA_GSDer35(1-2.5) для определения суммы трансЖК $(T T)$ в масложировых смесях; внизу - спектры оптической плотности $D$ для 23 калибровочных образцов масложировых смесей, полученные в фурье-спектрометре МРА (Брукер, Германия).

реляции $R$ (достоверности) и стандартной ошибки $S E C$. Кроме ПЛС-моделей для предсказания содержания клинически важных С4:0, C14:0, С16:0 и С18:1 ЖК были построены модели для оценки параметров ПЛСрегрессии по спектрам образцов с содержанием двух мажорных ЖК - стеариновой С18:0 и линолевой $\mathrm{C} 18: 2$, которые аналогичны олеиновой ЖК по длине углеродной цепи и, возможно, „мешают“ определению последней, что следует из результатов отнесения обертонов и комбинаций в БИК-спектрах поглощения образцов к колебаниям связей функциональных групп молекул ЖК по данным работы [18].

Поскольку в аналитической практике понятие селективности не определено однозначно [19], оценим селективность как отношение вкладов в стандартную ошибку определения аналита, возникающих из-за вариации долей аналита и вариации „мешающего“ компонента в образцах тестирующих партий.

Селективность определения аналита при мешающем действии матрицы мы изучили на примере олеиновой ЖК С18:1 двумя способами в соответствии с [16]: а) сравнением векторов регрессионных коэффициентов для C18:1 и её структурных аналогов - стеариновой $\mathrm{C} 18: 0$ и линолевой $\mathrm{C} 18: 2$ ЖК и б) численной оценкой вклада в значение стандартной ошибки SEC определения ЖК С18:1, связанного со значительной вариацией содержания „мешающего“ компонента в тестирующей партии.

Как известно [17], параметр ПЛС-регрессии - вектор регрессионных коэффициентов $W$, позволяет:

а) выбрать участки спектров, которые содержат значимые для определения каждой ЖК регрессионные коэффициенты;

б) построить максимально селективные модели на участках спектров, которые не перекрываются с участками, значимыми для определения „мешающего“ компонента, и оценить их достоверность и погрешность по тестирующим образцам;

в) сравнить результат определения долей ЖК „селективными“ моделями и моделями на полных спектрах, выбрать из них оптимальную модель для каждого аналита.

Эффективность ПЛС-моделей для сыворотки сначала была оценена методом „leave-one-out“ в соответствии c [17] по величине коэффициента множественной корреляции $R$ и стандартной ошибке $S E C$. Далее мы протестировали каждую модель по образцам сыворотки из других партий, которые не использовали для калибровки. В образцах сыворотки крови для предсказания содержания клинически важных C16:0, C18:1 и С18:2 ЖК, кроме ПЛС-моделей, были построены модели для оценки параметров ПЛС-регрессии спектров с содержанием общих триглицеридов $T g$ и холестерина $C h$, которые, возможно, могут иметь значения для клинической диагностики.

Выбранные по результатам тестирования калибровочные модели для масложировых смесей, отмеченные в табл. 3 жирным шрифтом, использованы затем для оценки качества продуктов питания и БАД.

\section{Результаты и обсуждение}

Калибровочные модели, построенные для масложировых смесей по спектрам фурье-спектрометра для четырех спектральных диапазонов (включая полный), при однократном сглаживании и дифференцировании спектров при тестировании восемнадцатью образцами дают близкую погрешность, причем модель для диапазона $1.0-1.9 \mu \mathrm{m}$ имеет меньшие значения стандартной ошибки SEP даже по сравнению с моделью по спектрам полного диапазона, а также по сравнению с моделью MPA_2GSDer35(1-2.5) при двукратном дифференцировании (табл. 3).

Модели по спектрам фурье-спектрометра для определения аналогов олеиновой ЖК показали слабую корреляцию спектров с вариацией стеариновой С18:0 ЖК и отчетливую корреляцию (коэффициент множественной корреляции $R=0.91$ ) для линолевой С18:2 ЖК. Нами было установлено, что парная корреляция массовых долей олеиновой и линолевой ЖК в партии стандартных образцов не превышала 25\%. Отсюда следует возможность „мешающего“ действия последней. Модель, построенная по участкам спектра вблизи $1100 \mathrm{~nm}$ (обертон 
Таблица 3. Параметры $(n, R, S E C)$ моделей, поименованных в столбце 1 по типу спектрометра (фурье - МРА, дифракционный - IGA), по способу обработки спектров (GSDer - сглаживание по Голею-Савицкому и дифференцирование; 2GSDer - то же двукратно, MSC - коррекция многократного рассеяния), по числу калибровочных образцов и по спектральному диапазону (в $\mu \mathrm{m})$ для определения сумм насыщенных ЖК $(S F A=14: 0+16: 0+18: 0)$, ненасыщенных ЖК $(U S F A=18: 1+18: 2+20: 4)$, их отношения $r=S F A / U S F A$ и суммы транс-жиров $(T=\mathrm{C} 18: 1$ trans $+\mathrm{C} 18: 2$ trans $)$ для масложировых смесей

\begin{tabular}{|c|c|c|c|c|}
\hline Параметры & \multirow[t]{2}{*}{$S F A$} & \multirow[t]{2}{*}{$U S F A$} & \multirow[t]{2}{*}{$r=S F A / U S F A$} & \multirow[t]{2}{*}{$T T$} \\
\hline Модель & & & & \\
\hline $\begin{array}{l}\text { MPA_GSDer35 }(1 .-2.5) \\
\text { MPA_GSDer35(1.-1.9) } \\
\text { MPA_GSDer35 }(1 .-1.65) \\
\text { MPA_GSDer35(1.6-2.5) } \\
\text { MPA_2GSDer35(1-2.5) } \\
\text { MPA_MSC35 }(1-1.9) \\
\text { IGA_GSDer 35 } \\
\text { IGA_GSDer 48 } \\
\text { IGA_MSC48 } \\
\text { IGA_2GSDer48 } \\
\text { IGA_2GSDer46_O } \\
\text { IGA_Rb_46_TT } \\
\text { IGA_GSDer_48_P_ }\end{array}$ & $\begin{array}{l}5 ; 0.89 ; 1.1 \\
4 ; 0.94 ; 0.8 \\
4 ; 0.91 ; 1.0 \\
6 ; 0.77 ; 1.4 \\
5 ; 0.90 ; 1.1 \\
7 ; \mathbf{0 . 9 4 ; 0 . 8} \\
4 ; 0.91 ; 1.5 \\
\mathbf{6} \mathbf{0 . 7 7} \mathbf{1 . 4} \\
5 ; 0.89 ; 1.1 \\
4 ; 0.94 ; 0.8 \\
4 ; 0.91 ; 1.2 \\
\mathbf{6} \mathbf{0 . 9 4 ; 0 . 4} \\
8 ; 0.94 ; 0.9\end{array}$ & $\begin{array}{l}8 ; 0.81 ; 1.8 \\
6 ; 0.92 ; 1.1 \\
7 ; 0.91 ; 1.2 \\
9 ; 0.81 ; 1.6 \\
5 ; 0.89 ; 1.5 \\
\mathbf{4} \mathbf{0 . 7 4 ;} \mathbf{1 . 7} \\
5 ; 0.93 ; 1.7 \\
\mathbf{6 ; 0 . 8 7 ; 1 . 2} \\
8 ; 0.89 ; 1.3 \\
4 ; 0.96 ; 0.9 \\
4 ; 0.97 ; 1.0 \\
\mathbf{7} \mathbf{0 . 9 1 ; 1 . 0} \\
8 ; 0.89 ; 1.9\end{array}$ & $\begin{array}{l}5 ; 0.84 ; 1.2 \\
6 ; 0.82 ; 1.4\end{array}$ & $\begin{array}{l}6 ; 0.84 ; 0.6 \\
3 ; 0.91 ; 0.7\end{array}$ \\
\hline
\end{tabular}

колебаний $\mathrm{C}=\mathrm{C}$ ) и $1450 \mathrm{~nm}$ (комбинация колебаний $\mathrm{C}-\mathrm{H}$ и $\mathrm{C}=\mathrm{C})$, при тестировании партией из 25 образцов показала значительно большие коэффициенты корреляции $R$ для олеиновой С $18: 1$ ЖК, чем для линолевой $\mathrm{C} 18: 2$ ЖК $(R=0.84$ и $0.43, S E C=1.36$ и 2.8 для олеиновой и линолевой ЖК соответственно), т. е. олеиновой ЖК линолевая не мешает. С другой стороны, модель MPA_MSC35(1-1.9) показала более устойчивые параметры при вариации стеариновой С18:0 ЖК и была выбрана для опробования на масложировых продуктах.

Влияние предобработки спектров на модели незначительно, однако удаление общей базовой линии в спектрах или дифференцирование спектров улучшает параметры определения олеиновой С18:1 ЖК. ЖК с различной изомерной формой показывают различные величины регрессионных коэффициентов вблизи длин волн 1160-1220 nm, например для элаидиновой трансЖК и олеиновой цис-ЖК. ЖК с различным числом атомов углерода при увеличении числа атомов С в цепи ЖК имеют нарастающий сдвиг пика вектора регрессионных коэффициентов вблизи длин волн $1400 \mathrm{~nm}$ в „жесткую“ область спектра. Следовательно, с помощью модели по избранным участкам спектра олеиновую ЖК можно определять более селективно, однако значение ошибки увеличилось по сравнению с моделью по „полным“ спектрам; модель стала „грубой“ из-за уменьшения массива статистики. Поэтому для определения уровня ЖК С18: 1 в неизвестном образце целесообразно применить „грубую“, но селективную модель, а затем модель по полным спектрам, но, может быть, включающую косвенные корреляции, и сравнить их показания. Если последние совпадают в пределах погрешности „полной“ модели, то можно быть уверенным в том, что матрица образца полно представлена калибровочными образцами, а определение происходит селективно.

Для численной оценки селективности „грубой“ модели спектры полного диапазона 14 образцов партии № 2 co значительной (около \pm 30 mass \% по данным хроматографии) вариацией доли олеиновой ЖК и с одинаковым значением (в пределах \pm 0.02 mass \%) доли линолевой ЖК были использованы для определения доли олеиновой ЖК. При этом стандартная ошибка $S E C$ составила 1.83 mass \%. Затем, доля олеиновой ЖК была определена той же моделью в 12 отобранных образцах с одинаковой долей $( \pm 0.03$ mass \%) олеиновой ЖК и значительной вариацией доли линолевой ЖК (около \pm 20 mass \%), при этом значения SEC оказалось 1.92 mass \%. Поскольку было установлено, что содержание линолевой ЖК сильно коррелирует со спектрами полного диапазона, можно считать, что вклад в значения SEC в размере 0.09 mass \% произошел из-за вариации линолевой ЖК, т. е., селективность „грубой“ модели по олеиновой ЖК - 95\%. Оценка селективности „полной“ модели по тем же спектрам показала значения SEC для партий из 14 и 12 образцов 1.41 и 1.80 mass \% соответственно, что соответствует значению селективности ,полной“ модели $78 \%$.

Фурье-спектры поглощения и данные о содержании суммы транс-ЖК (ТТ) масложировых образцов партии № 3 показали заметную корреляцию вблизи 1200 и $1450 \mathrm{~nm}$ по вектору регрессионных коэффициентов WTT в модели MPA_MSC35(1-1.9), см. рис. 3. Этот факт мы использовали для построения ПЛС-модели с помощью IGA-спектрометра и получили хорошие параметры определения TT (IGA_Rb_46_TT, табл. 3 и рис. 4), которую 
Таблица 4. Определение содержания мажорных насыщенных миристиновой, пальмитиновой и стеариновой ЖК $($ НЖК $=14: 0+16: 0+18: 0)$, ненасыщенных олеиновой, линолевой и арахидоновой ЖК (ННЖК $=18: 1 \mathrm{c}+18: 2 \mathrm{c}+20: 4 \mathrm{c})$, их отношения $r=$ НЖК/ННЖК и суммы транс-ЖК $(T T)$ в БАД, спрэдах и сливочных маслах для их идентификации

\begin{tabular}{|c|c|c|c|c|c|c|c|c|}
\hline Содержание ЖК & \multirow[t]{2}{*}{ 14:0 } & \multirow[t]{2}{*}{$16: 0$} & \multirow[t]{2}{*}{$18: 0$} & \multirow[t]{2}{*}{$18: 1 \mathrm{c}$} & \multirow[t]{2}{*}{$18: 2 \mathrm{c}$} & \multirow[t]{2}{*}{$20: 4 \mathrm{c}$} & \multirow[t]{2}{*}{$r$} & \multirow[t]{2}{*}{$T T$} \\
\hline Наименование & & & & & & & & \\
\hline Говяжий жир № 17 & 3.21 & 24.7 & 16.42 & 42.93 & 1.83 & 0.05 & 0.95 & 3.95 \\
\hline МЖ № 8 & 10.39 & 27.5 & 13.7 & 23.86 & 2.14 & 0.14 & 1.13 & 3.32 \\
\hline МЖ № 3 & 10.9 & 38. & 11.3 & 18.3 & 0.3 & 0.08 & 3.11 & 1.34 \\
\hline Пальм. масло № 1 & 1 & 43.8 & 4.42 & 39.14 & 9.9 & & 1.1 & 0.27 \\
\hline Маргарин ЗНАТИН & 0.88 & 37.1 & 4.3 & 35.1 & 20.8 & 0.1 & 0.76 & 0.52 \\
\hline Маргарин ПЕЧКА & 0.82 & 33.6 & 5.6 & 34.77 & 13.27 & & 0.85 & $>5$ \\
\hline БАД „Доппельгерцактив“ & & 18.1 & & 11.4 & 2. & & 1.25 & 3.2 \\
\hline БАД „Биафишенол“ & & 13.4 & & 23.6 & $>10$ & & 0.63 & 1.8 \\
\hline Спред „Кремлевское“ & & 11.2 & & 6.1 & 29.2 & & 0.33 & $>5$ \\
\hline Спрэд „Extra“,72\% & & $<5$ & & 12.2 & 30.3 & & $<0.12$ & 4.8 \\
\hline Масло „Из Василькова“ & & $<5$ & & 4.1 & 32.9 & & $<0.17$ & $>5$ \\
\hline Заменитель м.ж.„Еfko“ & $<1$ & 21.5 & $<4$ & 2.6 & 44. & & $<0.5$ & 4.1 \\
\hline
\end{tabular}

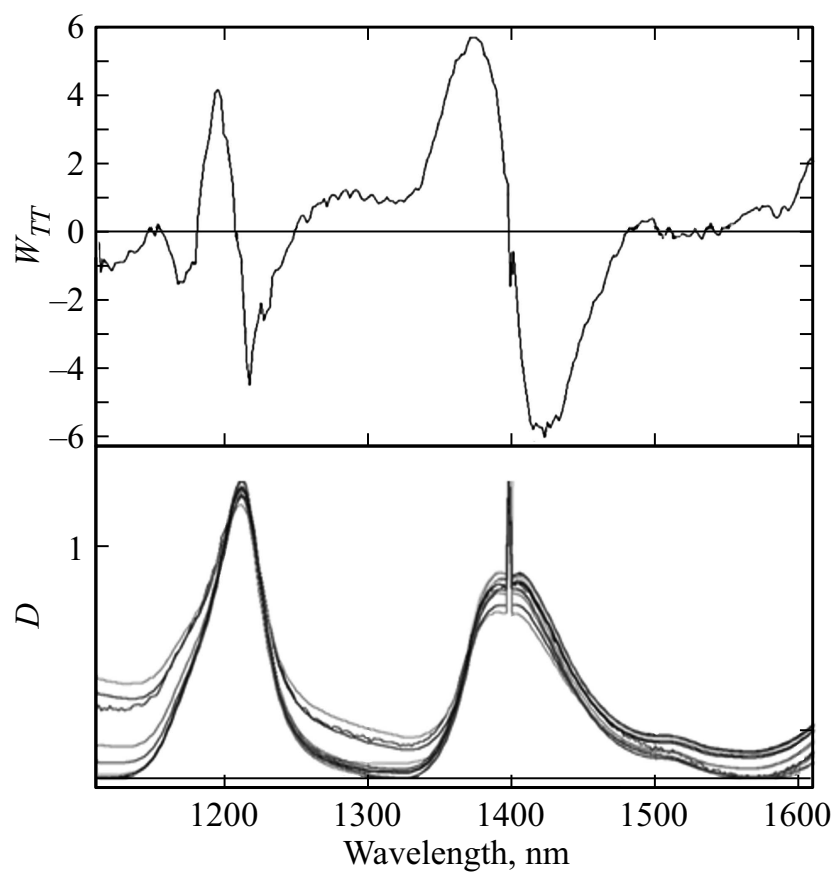

Рис. 4. Вверху - вектор регрессионных коэффициентов WTT для суммы транс-ЖК; внизу - спектры оптической плотности $D$ для 23 калибровочных образцов жиромасляных смесей, полученные в портативном IGA-спектрометре. Пик при длине волны $1400 \mathrm{~nm}$ - дефект элемента линейки фотодиодов.

применили для экспресс-анализа покупных масел, спредов и топленых жиров, поименованных в табл. 4.

В образцах сыворотки крови, кроме ПЛС-моделей, для предсказания содержания клинически важных С16:0, C18:1и С18:2 ЖК были построены модели для оценки параметров ПЛС-регрессии спектров с содержанием $C h$, которые, возможно, „мешают“ определению ЖК. Для оценки возможного влияния на определение олеиновой
ЖК использованы результаты отнесения обертонов и комбинаций в БИК-спектрах поглощения образцов к колебаниям $\mathrm{C}=\mathrm{C}$-связи по данным работы [18]. Мы воспользовались этим параметром для выбора участков спектра, характеризующих колебания $\mathrm{C}=\mathrm{C}$ - и $\mathrm{C}-\mathrm{H}$ связей в ЖК C18:1 для построения моделей GSDer и 2GSDer и получили для них наилучшие значения достоверности и погрешности определения ЖК С18:1.

Параметры выбранных по результатам тестирования лучших калибровочных моделей для диапазона $0.9-1.8 \mu \mathrm{m}$ имели значения стандартной ошибки $S E P$ $0.97 \%, 0.91 \%$ и $0.82 \%$ для $T G$ и $C h$ соответственно.

Профиль ЖК сыворотки крови пациентов характеризуется двумя признаками: относительно высоким содержанием линолевой ЖК и группировкой по отношению суммы $(S)$ мажорных насыщенных (миристиновой, пальмитиновой и стеариновой ЖК) к сумме мажорных ННЖК (олеиновой, линолевой и арахидоновой ЖК) в два пула со средними значениями $S 1=0.23$ при $S E C=0.04$ и $S 2=0.58$ при $S E C=0.08$, что может представдять интетрес для кардиологической практики.

С другой стороны, статистический анализ хроматографических данных о содержании пальмитиновой, олеиновой и линолевой ЖК в сыворотке показал высокие значения парной (по Пирсону) корреляции между ними. Это обстоятельство позволяет ограничиться определением одной из них, что снижает требования к чувствительности метода и облегчает достижение необходимых метрологических параметров анализа. Сравнение векторов регрессионных коэффициентов для триглицерида олеиновой ЖК в глицерине с 8\%-ми воды, полученных с помощью БИК фурье-спектрометра в работе [20], показывает отсутствие влияния полосы связи -OH (вблизи длин волн 1170 и $1440 \mathrm{~nm}$ ) в последних. Построенные модели позволяют определять содержание С16:0, цис- 
C18:1 и транс-C18:1 + транс-C18:2 на фоне 2-6\%ного содержания воды без помех.

Как отмечено выше, спектральный диапазон имеющегося IGA-спектрометра не является наиболее благоприятным для определения содержания клинически значимых ЖК. Однако наилучшие по результатам тестирования калибровочные модели IGA-спектрометра мы использовали для экспресс-анализа транс-ЖК в продуктах. Так, определение содержания суммы С $18: 1$ транс и C18:2mранс ЖК в маслах и жирах (табл. 4) позволило сделать заключение о соответствии в них содержания транс-ЖК тем сведениям, которые заявлены производителем. Эти данные позволяют определить количество масложировых продуктов, содержащее безопасную суточную дозу транс-ЖК для человека $<1 \mathrm{~g} /$ day [21], а также указывают на существенное число подделок в БАД и масложировых продуктах.

\section{Заключение и выводы}

В настоящей работе показано, что индивидуальные триглицериды диагностически значимых ЖК (C4:0 масляной, С14:0 миристиновой, С16:0 пальмитиновой, C18:1 олеиновой, С18:2 линолевой, суммы транс-ЖК) в сыворотке крови можно оперативно и селективно диагностировать без пробоподготовки с применением БИКспектрометра в диапазоне длин волн $1100-1800 \mathrm{~nm}$.

Другой результат состоит в доказательстве эффективности применении для определения названных ЖК созданного нами портативного IGA-спектрометра в комбинации с усовершенствованным методом многокомпонентной калибровки - ПЛС-регрессией для массового контроля показателей качества масложировых продуктов, а также для экспресс-оценки профиля ЖК в сыворотке крови. Сочетание обоих подходов позволяет интенсифицировать терапию сердечно-сосудистых заболеваний, а также повысить эффективность диетотерапии с целью профилактики атеросклероза, метаболического синдрома и синдрома инсулино-резистентности.

Перспектива метода состоит еще и в повышении чувствительности IGA-спектрометра к минорным содержаниям транс-ЖК, что позволит изучить влияние на организмы транс-ЖК натурального и искусственного происхождения.

\section{Благодарности}

Авторы глубоко благодарны к.т.н. Е.А. Юровой, зав. лабораторией Техно-химического контроля ВНИИ молочной промышленности, за предоставление и стандартизацию образцов и к.ф.-м.н. Н.Ю. Болдыреву за регистрацию спектров партий образцов с применением фурье-спектрометров.

\section{Соблюдение этических стандартов}

Настоящая статья не содержит каких-либо исследований с участием людей в качестве объектов исследований.

\section{Конфликт интересов}

Авторы заявляют, что у них нет конфликта интересов

\section{Список литературы}

[1] Hunter J.E., Zhang J., Kris-Etherton P.M. // Am. J. Clin. Nutr. 2010. V. 91. N 1. P. 46.

[2] Титов В.Н., Ариповский А.В., Каба С.И., Колесник П.О., Веждел М.И., Ширяева Ю.К. // Клин. лаб. диагн. 2012. T. 7. № 3. С. 8.

[3] Da Silva M.S., Julien P., Bilodeau J.F., Barbier O., Rudkowska I. // Lipids. 2017. V. 52. N 4. P. 315.

[4] Petibois C., Cazorla G., Cassaigne A., Dólóris G. // Appl. Spectrosc. 2002. V. 56. N 10. P. 259.

[5] Gebauer S.K., Destaillats F., Dionisi F., Krauss R.M., Baer D.J. // Am. J. Clin. Nutr. 2015. V. 102. N 6. P. 1339.

[6] Hernández E.Á. et al. // J. Clin. Invest. 2017. V. 127. N 2. P. 695.

[7] Mossoba M, Azizian H., Kramer J. Application of Infrared spectroscopy to the rapid determination of total saturated, trans, monounsaturated, and polyunsaturated fatty acids. 2012. [Электронный ресурс] Режим доступа: http://lipidlibrary.aocs.org/topics/IR-trans/index.htm

[8] Zhao M., Beattie R.J., Fearon A.M., O'Donnell C.P., Downe G. // Int. Dairy J. 2015. V. 51. P. 41.

[9] „FTNIR Analyzers vs. Dispersion Spectrometers: A Comparison“. 2018. [Электронный ресурс] Режим доступа: https://www.azom.com/article.aspx?ArticleID =17314

[10] Kalinin A., Krasheninnikov V., Sadovskiy S., Denisovich E., Yurova E.J. // J. Near Infrared Spectr. 2008. V. 16. N 3. P. 343.

[11] Westad F., Schmidt A., Kermit M. // J. Near Infrared Spectr. 2008. V. 16. N 3. P. 265.

[12] Kalinin A.V., Krasheninnikov V.N., Sviridov A.P., Titov V.N. // J. Appl. Spectr. 2016. V. 83. N 5. P. 811.

[13] Калинин А.В., Крашенинников В.Н., Свиридов А.П., Титов В.Н. // Клин. лаб. диагн. 2015. Т. 60. № 11. С. 13.

[14] Клименко Л.Ю., Петюнин Г.П. // Украинский мед. альманах. 2013. T. 16. № 1. С. 71.

[15] Орлова Т.И., Уколов А.И., Савельева Е.И., Радилов А.С. // Аналитика и контроль. 2015. Т. 19. № 2. С. 183.

[16] Юрова Е.А., Калинин А.В., Тарабукин И.В. Патент РФ № 129251,2012 .

[17] Wold S., Sjostrom M., Eriksson L. // Chem. Intelligent Laboratory Systems. 2001. V. 58. N 7. P. 109.

[18] Brian G. Osborne. Near Infrared Spectroscopy in Food Analysis, Encyclopedia of Analytical Chemistry. 2006. [Электронный ресурс] Режим доступа: https://doi.org/10.1002/9780470027318.a1018

[19] Краснянчин Я.Н., Пантелеймонов А.В., Холин Ю.В. // Методы и объекты химического анализа. 2010. Т. 5. № 3. C. 118.

[20] Kalinin A., Krasheninnikov V., Sadovskiy S., Yurova E. // J. Near Infrared Spectr. 2013. V. 21. N 5. P. 409.

[21] Titov V.N. // Pathogenesis. 2013. V. 11. N 1. P. 18. 